\title{
A Mixed-Method Case Study: Is there Only the Pictorial Input that Affects Word Retention?
}

\author{
Watjana Suriyatham \& Watcharee Paisart* \\ ${ }^{1}$ Language Institute, Thammasat University, 2 Prachan Road, Khet Pranakorn, Bangkok 10200, Thailand
}

Corresponding Author: Watcharee Paisart, E-mail: watcharee.paisart@gmail.com

\begin{abstract}
ARTICLE INFO
Article history

Received: February 06, 2018

Accepted: April 15, 2018

Published: July 01, 2018

Volume: 7 Issue: 4

Advance access: May 2018

Conflicts of interest: None

Funding: None

ABSTRACT

This mixed-method case study was conducted to probe how a set of pictures had an influence on a group of EFL university students' retention of English words. Seven Thai university participants, enrolling in the course of English for Service Industry, were voluntarily engaged in the study. They took a pretest of 45 words they learned in class through the use of pictorial input for one semester, and right after the posttest, they recalled how they could remember the words in an individually stimulated recall protocol session. The result of T-test from Wilcoxon sign-ranked test showed that the pretest and posttest scores were significantly different at the 0.05 level. Interestingly, the qualitative accounts from the stimulated recall revealed that apart from the pictorial input the participants learned in class, they also employed other strategies to help them memorize the vocabulary. The findings from the study; therefore, shed lights on cognitive-metacognitive processing and strategies an individual EFL learner adopted, and most importantly, on how teachers can encourage their learners to orchestrate them and make the best use of pictures in order to learn ESP vocabulary effectively.
\end{abstract}

Key words: Pictorial Input, Word memory, Word retention, Vocabulary, Stimulated Recall Protocol

\section{INTRODUCTION}

\section{Importance of Vocabulary in English Language Learning}

Vocabulary knowledge is considered both necessary and important for language learners. Laufer (1977) argued that vocabulary is central, not only because of its importance for language learning but also for actually using it. If the learners do not know the key words' meanings in a sentence, it is unlikely that they will be able to get the gist of what is being communicated, leading to communication failure. According to Nation (2001), he stressed that "Words are not isolated units of language, but fit into many interlocking systems and levels" (p. 23). With a good command of words, communication in both the receptive and productive sense can proceed. Further importance to words is advocated by Thornbury (2002), who pointed out that grammatical knowledge is less crucial for effective communication compared to knowledge of vocabulary. That is an interlocutor, with decent word knowledge but poor or basic of grammar, can still understand the content. On the contrary, if s/he has little knowledge about the words used in a sentence, it is highly unlikely that mutual understanding will actually occur. In an attempt to support the students to learn words efficiently, a group of language teachers and researchers have tried to identify effective strategies for vocabulary learning. Nation (2001) suggested that teachers should find effective and appropriate ways to teach vocabulary to language learners in order to alleviate word burden thus making language learning easier for them. Language researchers tend to focus on vocabulary strategies and techniques that facilitate students to learn new words (File \& Adams, 2010; Hummel, 2010; Mizumoto \& Kansai, 2009; Nemati, 2013; Yang \& Dai, 2012).

\section{Picture Usea and its Significance to Language Learning}

Among the discussion mentioned earlier, pictures have also been used in vocabulary learning and teaching and it has been reported that teaching through pictures is both practical and effective because pictures can activate learners' ideas and concepts in relation to what they are studying. Harmer (2001, p. 135) supported the idea of using pictures in word learning in that they contribute to the understanding of words thus making their meaning clearer to language learners. Moreover, Nelson and Reed (1976) added that effective use of pictures would lead to positive output and good learning.

The use of pictures is advantageous since it is believed that pictures help word learning and retention if used in conjunction with word presentation (Paivio, 1976; Underwood, 1989). Baddeley (1990) also explains the importance of visual imagery for memory retention and argues that people 
have utilized imagery as a mnemonic aid for centuries to facilitate learning and enhance memory. So the studies and research about the use of pictures to support word retention swing back to be focused on at the moment. Even in a conversation class, pictures can also be used as a stimulus for conversation and discussion development (Wright, 1989). In a class, students who learn English conversation, especially with non-native teachers and classmates may find the conversation not authentic because they do not have a chance to hear the conversation with native speakers. Then, if they need to generate conversation by themselves, it might not be interesting or attractive. Therefore, using pictures could attract them and engage them into more vivid conversation. This idea is further supported by Vazques \& Chiang (2014) who claim that the brain processes words as very small pictures. Such image conversion taking place in the brain might assist in organization and long-term storage leading to better retention. Studies on visual input processing have shown that pictures are indeed recognized and recalled much better than isolated word (picture superiority effect) (Stenberg, 2006).

\section{Previous Studies}

A number of previous studies have investigated the strategies that have been employed to learn and teach vocabulary. Yang and Dai (2012) studied "the vocabulary memorizing strategies" among Chinese University students by distributing questionnaires to 68 students. The results revealed that four strategies were the most common: rote repetition, structural associations, semantic strategies, and mnemonic keyword techniques. In their conclusion, structural associations and semantic strategies were the most frequently strategies. They also suggested that memorial strategies should be practiced and manipulated during learning so as to encourage active vocabulary usage. Nemati (2013) has also conducted research into vocabulary learning strategies. In a study with 303 participants, half the samples were divided into an experimental group and half into a control group. The experimental group was trained with vocabulary learning strategies in class. The results revealed that students taught with strategies performed better than those that did not use strategies. Moreover, good language learners showed that they use various strategies. The interesting point was that imagery (one of the strategies used in this study) was reported to support vocabulary memory in both short-term and long-term memory for all students (low, intermediate, and high students). That means students from all levels of performance could remember vocabulary in both short-term and long-term memories. The picture was effective for vocabulary learning to all kinds of students.

Pictures have been used in English language teaching to investigate word retention and various aspects in some extent such as to stimulate English conversation, to lead to topic to discuss, etc. Hashemi, \& Pourgharib (2013) examined how instruction influenced the learning of vocabulary. They used a quasi-experimental approach, 39 participants divided into two groups: one studied vocabulary with the use of visual instruction and the other group studied vocabulary the traditional way: read text and do exercises or give vocabu- lary list and translate into L1. The results revealed that the group with receiving visual instructions outperformed the control group in terms of both learning and retention. In a related study that compared the effects of songs, pictures, and keywords on L2 vocabulary recognition and production, (Zarei, A.A., and Salimi, A. (2012), three different groups of participant received different methods of instruction following a pre-test to establish their vocabulary knowledge. In a posttest designed to measure receptive and productive aspects of vocabulary, Zarei and Salimi reported that the picture group had the overall best performance, followed by the keyword group, and then the song group.

These are some examples of the studies on vocabulary learning and the use of pictures, for example, one of these was the study of Hashemi and Pourgharib (2013). They studied the effect of visual instruction on new vocabularies learning. They divided students into two groups and used the posttest to collect the data after they had implemented the treatment. The control group was treated traditionally while the experimental group was treated visually. The results showed that visual learning was more effective for learning new vocabulary.

Apparently, most studies were designed by using a quasi-experiment, an approach which is quite unlikely to control extraneous influences individual learners might experience in their daily life. Therefore, this research study aims to bridge the gap by using a mixed method case study to collect data both quantitatively and qualitatively. There is no control group. It allows the volunteer participants to acquire their vocabulary through the use of pictorial input when they learn with their peers in class, and to expose themselves with English outside class through various channels such as social media, films, TV and newspapers. In addition to the pretest-posttest design, the study employs a qualitative methodology, stimulated recall protocols, to probe how the participants retrieve their word retention by using the picture stimuli. Moreover, the goal is to see if any related factors involved in vocabulary memory so as to design for appropriate activities or lesson for more efficiency in teaching vocabulary. To discover an in-depth information, the following questions are investigated.

(1) Do pictures really help students remember words?

(2) How can the participants retrieve words when they see pictorial stimuli?

(3) Are there any factors affecting word retention?

\section{METHODOLOGY}

\section{Participants}

There were seven $2^{\text {nd }}$ year student volunteers from Tourism and Hotel major from a university in Thailand willing to take part in the study. They enrolled in an ESP course, English for Service Industry, which was a compulsory course for their major. All student volunteers took the ESP course with the same teacher, who used the same materials and activities, thus exposing the students to the exact same input of pictures, audio, and PowerPoint presentations with the exact same evaluation criteria. 


\section{Research Tools}

There were four instruments used in the study: pretest, posttest, teaching pictorial materials (or teaching material), and stimulated recall protocol, which is the main research method to collect the qualitative data.

According to Gass and Mackey (2000, p.1), stimulated recall is "one subset of a range of introspective methods that represents a means of eliciting data about thought processes involved in carrying out a task or activity." The participants are stimulated by a stimulus such as video, audio and written performance to recall their cognitive, metacognitive processes and even the reasons they made while they were performing a task. Polio, Gass and Chapin (2006) compared between a stimulated recall with a post-task interview, and they claimed that stimulated recall could prompt participants with "visual reminder of events in different forms such as video or completed task on paper", while post-task interviews cannot. Therefore, they conclude that "rely on memory without prompts, hence making the result less accurate" (Polio, Gass and Chapin, 2006, pp. 242-3). Suriyatham (2013) adopted a consecutive stimulated recall protocol to probe listening strategies use while completing listening tasks, and found that it is a valid methodological tool to gain qualitative accounts reflecting the thought process as a result of supportive stimuli to help the participants recall. Brunfaut and McCray (2015) examined the cognitive processing of 25 test-takers with different CEFR levels while doing Aptis reading tasks by using a combination of eye-tracking and stimulated recalls. They reported that "Methodologically, the combined use of eye-tracking and stimulated recalls proved achievable and, moreover, fruitful. The two methods allowed balancing the strengths and weaknesses of each individual method, generating a richer and wider-reaching set of data than each alone, and allowing triangulation of the findings of each method" (Brunfaut and McCray, 2015, p.2).

\section{Pilot Study/Creating and Validating Data Collection Tools}

Before initiating the stimulate recall protocol described above, pretest and posttest were used. Then, after computing the comparison scores from the pretest and the posttest, the stimulated recall protocol was later performed. Both the pretest and the posttest consisted of 45 pictures that matched some of the words learned during the course ( 5 words per a unit $\mathrm{x} 9$ units in a semester). The students actually studied more than 45 words in the course, but these 45 words were selected to be taught according to the survey from former students who helped identify words that were most unknown and useful for them. Since they are expected to use English in their career after graduating, then, words that were useful for them were considered. These words were selected and mentioned by ex-students who finished the course and still in contact to give feedback with the teacher to develop the course continuously. Therefore, these 45 words were considered to match with the appropriate pictures to be taught in class. The pretest and posttest differed in terms of the order in which each unit was presented. In the pretest, Units 1-9 were presented sequentially whereas, the presentation orders were random in the posttest. Test sheets were distributed with only pictures provided and a blank below each picture where students could write in the English word. The picture selection process is discussed in the following part.

A teaching material, one of the research tools, was a content sheet prepared by the teacher. The content sheet contained a vocabulary section, language points, exercises, and interesting notes to the students. The vocabulary section introduced the pictures which represented real-world objects in both the pretest and posttest. The pictures used in the pretest, posttest, and the teaching material, were selected systematically. The steps of choosing them are described in detail as follows:

1. The course of English for Service Industry contains a total number of glossary of 135 words. (9 units with 15 words per unit $=135$ words $)$. This present study selected 5 words per unit ( 9 units x 5 words $=45$ words in total). This was derived from Miller's magic number theory that suggests that the limits of short-term memory is on average $7 \pm 2$ chunks ( 5 or 9 bits) of information (Miller, 1956). Additionally, Finocchiaro and Bonomo's (1973) asserted that there should not be more than 8 vocabulary items presented at any one time and Vazquez and Chiang (2014) have also recommended that large numbers of words should not be presented in one chunk as these may disrupt retention. Word selection for each unit was determined by choosing items from the list that most students from each semester gave incorrect meanings in a Thai-English translation.

2. Pictures to match with these 45 vocabulary items were chosen from the Internet (Google image search). They were categorized equally into 5 different kinds of picture:

- Cartoon or animated pictures

- Realistic pictures

- Outstanding pictures

- Drawing pictures

- Pictures with words or texts written on

3. The pictures and the words were then checked by 5 experts who had background in teaching students for ESP course, especially students whose majors were Hotel and Tourism.

4. If a pair of word and picture was agreed by at least 3 out of 5 experts, that set would be accepted and incorporated into the material, but if it was rejected by two experts, the researcher would find a new picture to match with the word again, and send it to the experts to check again.

5. After receiving the final version from the experts' agreement, the words and pictures were piloted with a group of Tourism and Hotel students ( 9 students, who had previously taken this course). They were shown the pictures separated by the "topic of each unit (e.g. Operator, Waiter, Tour Guide, etc.), and requested to write in the words that they had studied and which they though relevant to the pictures. More than $50 \%$ of the pilot students got the correct answers for each picture. As a result, the words were applied in the teaching material, otherwise, the researchers should go back to the process of selection again. 


\section{DATA COLLECTION PROCEDURES}

This study took an entire semester to complete the data (15 weeks). The volunteer participants studied with their peer students in class, and they were all exposed to the same teaching materials, teaching style, media used in class, grading criterion, and testing. The procedures were explained below:

1. During the $1^{\text {st }}$ week of the semester, the pretest was distributed to all students who had enrolled in the course. The sheets containing the 45 pictures were distributed and the learners were told to label each picture with an English word. The learners were further instructed to write in Thai meanings if they could not think of an appropriate English word. While they were doing the test, color versions of the pictures were shown simultaneously on screen at the front of the class. Each picture was displayed for about ten seconds before being replaced by the next picture. Each picture was shown until the testing time ended (about an hour).

2. From the second to the fourteenth week, all students participated with normal provision of the teaching material. Power Point presentation was mainly used. There was some time that they were exposed to audio and multimedia sources. Both L1 and L2 were used in class, and the students were assigned to engage in their group work.

3. At the end of the semester (week 15) the posttest was implemented. The posttest was initiated in exactly the same manner as outlined for the pretest above.

4. After the posttest, all students except the 7 research participants were permitted to leave the room. In this step, stimulated recall protocol was implemented with research participants. Each of them was interviewed one by one. After checking the posttest results, they were asked to recall how or why they decided to write a particular vocabulary item for each particular picture. The checked posttest with pictorial stimuli was shown and it was used as the stimuli to prompt the participant to recall their retrospective cognitive process. Each volunteer spent about 20-30 minutes in the stimulated recall protocol procedure.

5. After finishing the data collection, the stimulated recall data was transcribed, and an inter-rater reliability on the coding was carried out by two experts $(\mathrm{r}=0.86)$. Additionally, the intra-rater results after leaving the first analysis coding for about 10 months was 0.83 .

6. Because of the small sample size of 7 participants, the pretest and posttest scores were analyzed by using the non-parametric statistics, Wilcoxon signed-rank test, and the findings from the stimulated recall protocol were transcribed, grouped into categories and computed into percentages.

\section{RESULTS}

The results are divided into two sections. The first section is to answer the first research question on whether the picture use has any effects on word retention. This part compares the pretest and the posttest scores using the Wilcoxon signed ranks test and the second part discusses the in-depth data derived from the stimulated recall protocol.

According to the results above, the null hypothesis is rejected. It means that pictorial input had an effect on word memory with the statistical significance level at .018. According to the Wilcoxon test, the significant level of 7 participants should be about 2 , but here it is. 018 so it could be concluded that the pictures affected word memory of the participants.

However, this particular result does not tell us whether other factors are involved in word memory. It is plausible that other factors were involved in increasing the scores from pre-test to post-test. To investigate further, in another section, we analyzed the stimulated recall protocol data to better understand the learning process of how the participants learn words from the pictorial input. This information is to answer the $2^{\text {nd }}$ research question on how the picture use affects word retention and the $3^{\text {rd }}$ research question on factors affecting word retention. The information derived consisted of various factors that involved in supporting vocabulary retention. The analysis of this part revealed some interesting findings, which are displayed in the following tables below. There were two parts of result presentations: Table 1 - presenting only the findings the participants reported on pictures helping them retrieve the vocabulary learned in class; and Table 2- showing other outstanding findings the participants recalled. The numbers mentioned in both tables represented

Table 1. Frequencies of using pictures to remember words

\begin{tabular}{|c|c|c|c|c|c|c|c|c|c|}
\hline No & Important findings & V1 & $\mathbf{V 2}$ & V3 & V4 & $\mathbf{V 5}$ & V6 & V7 & $\begin{array}{c}\text { Total of } \\
\text { frequency }\end{array}$ \\
\hline 1 & link the words to visual images & 11 & 17 & 3 & 8 & 7 & 5 & 13 & 64 \\
\hline
\end{tabular}

Table 2. Other strategy uses

\begin{tabular}{|c|c|c|c|c|c|c|c|c|c|}
\hline No & Important findings & V1 & $\mathbf{V 2}$ & V3 & V4 & V5 & V6 & V7 & Total \\
\hline 1 & $\begin{array}{l}\text { Known or seen words from other sources or learning } \\
\text { them from other courses during the semester }\end{array}$ & 11 & 10 & 10 & 16 & 8 & 11 & 8 & 7 \\
\hline 2 & Reviewing after studying in class & 4 & 4 & 14 & 3 & 8 & 0 & 4 & 37 \\
\hline \multirow[t]{2}{*}{3} & Using L1 translation & 3 & 0 & 4 & 2 & 1 & 0 & 8 & 18 \\
\hline & TOTAL & 18 & 14 & 27 & 21 & 16 & 11 & 20 & 129 \\
\hline
\end{tabular}


numbers of frequencies each student mentioned "how they remembered words" (each student learned 45 words equally) and those words they mentioned were all correct both the meanings and the spellings.

This finding means when learning vocabulary, the students used the pictures to help them memorize the words. Then, when they saw the pictures again, they could think of the words they learned. From Table 1, linking the words they learned with the visual image was mentioned 64 times by the participants. The maximum frequency of use was 17 whereas the minimum was 3 times. (If the participants could have remembered every word when they had seen the picture stimuli, the total frequencies would have been 45 words X 7 participants $=315$ times. That counts for only 20.3\%.) This suggests that pictorial input alone has a minimal effect on their word memory.

The following excerpts present the stimulated recall accounts from the participants.

\section{Linking the Words Learned to Visual Images}

"I feel like when I looked at the picture, then the word suddenly jumped into my mind."

(Extract 1: Volunteer 2)

"This word 'call light'. I remembered the picture and you also showed a video clip about this light when people get on board."

(Extract 2: Volunteer 3)

"This word is 'repeat'. I can remember from the picture that you taught. It was the picture of a teacher teaching students and this word is the word 'repeat'.

(Extract 3: Volunteer 4)

"Teacher.... I could remember because of the picture!!. I remember there are two pictures which are similar to each other (she showed the two pictures in the handout in front of her). This word 'cash', it is the picture of banknotes and coins.

(Extract 4: Volunteer 5)

Table 3 shows the significant level of pre and posttest scores that leads to conclude that pictures have some effects on vocabulary memory. Then, the findings in this part help to show clear accounts from the participants who applied these strategies besides the pictorial input.

The table below shows additional findings that were of interest, which could not be discovered through the experimental design alone.

Table 3 shows three findings which involve in the picture use on word retention. Each finding is discussed in detail below.

Table 3. The comparison of the pretest and posttest scores on the vocabulary test

\begin{tabular}{llll}
\hline Null Hypothesis & Sig. & Decision \\
\hline 1 & $\begin{array}{l}\text { The median of Pre } \\
\text { equals }\end{array}$ & 0.018 & $\begin{array}{l}\text { Reject the null } \\
\text { hypothesis }\end{array}$ \\
2 & $\begin{array}{l}\text { The median of Post } \\
\text { equals }\end{array}$ & 0.018 & $\begin{array}{l}\text { Reject the null } \\
\text { hypothesis }\end{array}$ \\
\hline
\end{tabular}

\section{Known Or Seen the Words from Other Sources in the Same Semester}

The first one, most students remembered words because they had learned those words from other subjects during that semester. They verbally reported they were familiar with the words at first sight although they could not remember the words immediately after encountering them. When they learned the words again in class it seemed that they could remember the words. As seen in Table 2, the overall frequency count for this particular reason was 74 .

"I think I've seen this word somewhere but I could not remember. When I studied this word in your class, then it jumped into my mind. Then, I could remember it."

(Extract 5: Volunteer 1)

"I have learned this word from another course about House Keeping. It looks accustomed. Then, when I learn it again in this class, I can remember it well."

(Extract 6: Volunteer 5)

Another interesting finding was studying, which was mentioned 37 times. This finding refers to the strategy that students worked hard on learning the words on their own when they were not in class. So, they could remember the words correctly.

\section{Reviewing after Studying in Class}

"I think I remembered this word because I studied it outside the class. I worked so hard to memorize it before the test. Then, I still remembered this word until now."

(Extract 7: Volunteer 4)

"At that time when I first saw this word I spelt it wrongly. Then, when you taught me, I tried to read the word and remembered it separately like 're-com-men-da-tion' and I remembered this pattern."

(Extract 8: Volunteer 7)

Additional reasons given were that Thai concepts were recognized rather than English words being remembered. This reason was provided on 18 occasions.

\section{Remembering by Using L1 Instead of the Target Language}

"When I studied this word at that time I could not remember English word but I remembered Thai meaning. I studied this word the same as other words but I could not think of English word, it just came out only Thai word."

(Extract 9: Volunteer 3)

"Koh-Ham......It is....Koh-Ham....Pid-Kod.Rabieb....I could only remember Thai. I could not remember English word. This word is strange."

(Extract 10: Volunteer 7)

Moreover, some interesting information was also evident for the 29 occasions in which the participants report remembering words incorrectly. They were certain that the meanings they wrote in the test paper were correct, but in fact they were not. 


\section{Falsely Recalled}

"I think this word is 'delay'. From the picture, it is like they are waiting for a delayed flight" (but actually, this word is 'cancellation')."

(Extract 11: Volunteer 7) "This one looks like the person in the picture got pain there, but I could not think about the word used, so I think she may have a backache (actually that word is 'stiffness').'

(Extract 12: Volunteer 1)

\section{CONCLUSION AND DISCUSSION}

The main purpose of this research was to investigate students' vocabulary learning via pictures in an in-depth manner. Many previous studies have revealed the benefit of pictures for word learning (Carpenter \& Olson, 2012; Hashemi \& Pourgharib, 2013; Hazamy, 2009; Vazquez \& Chiang, 2014; Zarei \& Salimi, 2012). However, it is important to note that the results from the experimental aspect of the current study do not show all sides of this phenomenon. To be able to remember words may consist of many factors, not just only pictorial input. Although Stenberg (2006) showed the importance of picture superiority for memory, he also mentioned that it has its limitations. The present study, then, helps to reveal deeper findings that perhaps illuminate some of the cognitive processes of students who studied words with pictorial material. Additionally, metacognitive strategies of the students could also be noticed. Metacognitive strategies are a type of learning strategies which students could apply in learning. According to Oxford (1990), there are three sub-categories (1) centering learning, (2) arranging and planning learning, and (3) evaluating learning. Danuwong (2006) explained about the executive metacognitive process that it could occur at any time: before, during, and after of completing the task. In this case, after the students learned vocabulary, they managed to review the words individually so cognitive and metacognitive were used interchangeably.

The main findings revealed that most students remember words because they have seen or known them, not only in the course the researcher was teaching but also from other sources or other subjects which were being implemented in the same semester. This finding is compatible with Wickelgren $(1977$, p. 7$)$, who has stated that memory must go through acquisition, storage, and retrieval. With respect to the current study, this suggests that students first saw the words, then they became familiar with them, while studying them again, they could remember and retrieve the words. Students who learn words in one subject may not be able to remember them within a short period of time, but if those words are heard or seen again in different contexts again and again, this might help to consolidate them and move from acquisition to long-term memory. Tavakoli \& Gerami (2012) studied the effect of keyword and pictorial methods on EFL learners' vocabulary learning and retention and found that the keyword method was discovered to be better than the pictorial method for long-term retention. Regarding study, it might be seen that some extent, pictures may also have some disadvantages when it comes to vocabulary learning.
Another important finding shows the effectiveness of picture use to support word memory. This is similar to the study of Zarei and Salimi (2012) who studied the comparative effects of song, picture and the keyword method on L2 vocabulary recognition and production. They found that the group with picture use performed better than the other two groups, namely song and keyword. Stokes (2002) also studied the effect of using pictures in teaching vocabulary. It is likely that students tend to prefer the use of pictures in vocabulary learning and those pictures have the tendency for easy remembering. Vazquez and Chiang (2014) pointed out some considerations for picture selection, arguing that the teacher should find pictures that are relevant to what is being taught. For example, teachers should avoid: (1) using small-size picture to present to students; (2) modifying the original size of the picture; and (3) using pictures that have distracting features (e.g. too bright or colorful). To highlight this point, Sokmen (1997) gave an interesting comment that if the pictures were created by the students themselves, they would help in vocabulary acquisition, at the early stages. Therefore, this can be suggested for further study on the use of picture on word retention to let students create pictorial input by themselves. It would be a very interesting study.

Studying the words themselves could be considered individual word learning or involving the use of memorizing strategies. For teachers, no matter how much they try to encourage students to learn and memorize words, if they do not have any interest or are not aware of the necessity of the vocabulary necessity or importance, there is probably little use. As Rivers (1983, p. 34) stated that teachers should not force students to learn vocabulary. They should learn by themselves so the vocabulary lasts in memory.

In conclusion, there are many factors influencing students' memory when it comes to learning and memorizing vocabulary. Pictures have been, widely favored because of their supposed superiority on long-term retention of verbal material and they have been widely promoted as a medium for encouraging L2 vocabulary acquisition. However, as this research study's findings suggest, the pictorial input alone might not be the only factor that affects word retention. Learners are individuals who have their own learning style and strategies or there might be other underlying factors that might help support language learning and memorizing of new words. As language teachers, it is challenging and necessary to discover those factors and find effective ways to manage and manipulate those things in the teaching for the best outcome of a language teaching and learning.

\section{REFERENCES}

Baddeley, A. (1990). Human Memory: Theory and Practice. Needham Heights. Massachusetts.

Brunfaut, T. and McCray, G. (2015). Looking into Test-Takers' Cognitive Processes While Completing Reading Tasks: A mixed-method eye-tracking and stimulated recall study. British Council.

Carpenter, S.K., and Olson, K.M. (2012). Are Pictures Good for Learning New Vocabulary in a Foreign Language? Only 
If You Think They Are Not. Journal of Experimental Psychology: Learning, Memory, and Cognition, 38, 92-101.

Danuwong, C. (2006). The role of metacognitive strategies in promoting learning English as a foreign language independently. Edith Cowan University. Research Online. Retrieved from http://ro.ecu.edu.au/theses/59

File, K.A. \& Adams, R. (2010). Should Vocabulary Instruction Be Integrated or Isolated? TESOL Quarterly, 44(2), 222-249.

Finocchiaro, W.S. \& Bonomo, M. (1973). The foreign language learner: a guide to teachers. New York: Regents Publishing Company.

Gass, S.M., and Mackey, A. (2000). Stimulated Recall Methodology in Second Language Research. Lawrence Erlbaum Associates, Inc., Publishers.

Harmer J. (2001). The Practice of English language Teaching. $3^{\text {rd }}$ ed. London: Longman.

Hashemi, M., and Pourgharib, B. (2013). The Effect of Visual Instruction on New Vocabularies Learning. International Journal of Basic Sciences \& Applied Research, 2(6), 623-627.

Hazamy, A.A. (2009). Influence of Pictures on Word Recognition. Electronic Theses \& Dissertation. 430. Georgia Southern University. Retrieve from https://digitalcommons.georgiasouthern.edu/etd/430

Hummel, K.M. (2010). Translation and short-term L2 vocabulary retention: Hindrance or help? Language Teaching Research, 14(1) 61-74.

Laufer, B. (1977). The lexical plight in second language reading. Cambridge: Cambridge University Press.

Lewis, M. \& Hill, J. (1985). Practical techniques for language teaching. England: Language teaching publication.

Miller, G.A. (1956). The magical number seven plus or minus two: Some limits on our capacity for processing information. Psychological Review, 63, 81-87.

Mizumoto, A. \& Kansai, O.T. (2009). Examining the effectiveness of explicit instruction of vocabulary learning strategies with Japanese EFL university students. Language Teaching Research, 13(4), 425-449.

Nation, I.S.P. (2001). Learning Vocabulary in Another Language. Cambridge University Press. Cambridge. pp. 33-34.

Nelson, DL., Reed VS, Walling JR. (1976). Pictorial Superiority. The Role of Pictures in Learning to Read. Educational Studies, 21, 119-131.

Nemati, A. (2013). Vocabulary Learning Strategies: A Short Way to Long Term Retention. Linguistics and Literature Studies, 1(1), 8-14.
Oxford, Rebecca L. (1990). Language Learning Strategies - What Every Teacher Should Know. Heinle \& Heinle, Boston, USA.

Paivio, A. (1976). Imagery in recall and recognition. in J. Brown (Ed.). Recall and recognition (pp. 103-129). New York, NY: Wiley.

Polio, C., Gass, S. and Chapin, L. (2006). Using Stimulated Recall to Investigate Native Speaker Perceptions in Native-Nonnative Speaker Interaction. SSLA, 28, 237-267.

Rivers, W.M. (1983). Communicating Naturally in a Second Language. Cambridge University Press.

Sokmen, A.J. (1977). Current trends in teaching second language vocabulary. in N. Schmitt \& M. McCarthy (Ed.). Vocabulary: Description, Acquisition and Pedagogy (pp. 237-257). Cambridge: CUP.

Stenberg, G. (2006). Conceptual and perceptual factors in the picture superiority effect. European Journal of Cognitive Psychology, 18(6), 813-847.

Stokes, S. (2002). Visual Literacy in Teaching and Learning: A Literature Perspective. Electronic Journal for the Integration of Technology in Education, 1(1), 10-19.

Suriyatham, W. (2013). The Development of Self-Access Materials for Listening Comprehension. Scholar Press.

Tavakoli, M., and Gerami E. (2012). The Effect of Keyword and Pictorial Methods on EFL Learner's Vocabulary Learning and Retention. Porta Linguarum, 19, 299-316.

Thornbury, S. (2002). How to teach vocabulary. London: Longman.

Underwood, J. (1989). Hypercard and Interactive Video. CALICO, 6, 7-20.

Vazquez, J.J., and Chiang, E.P. (2014). A picture is worth a thousand words (at least): The effective use of visuals in the economics classroom. International Review of Economics Education, 17, 109-119.

Wickelgren, W.A. (1977). Learning \& Memory. University of Oregon. Prentice-Hall, Inc. Englewood Cliffs. New Jersey. United States of America.

Wright, A. (1989). Pictures for Language Learning. Cambridge University Press.

Yang, W., and Dai, W. (2012). Vocabulary Memorizing Strategies by Chinese University Students. International Education Studies, 5(1), 208-215.

Zarei, A.A. and Salimi, A. (2012). The comparative effects of song, picture and the keyword method on L2 vocabulary recognition and production. Applied Research in English, 1(1), 43-56. 